\title{
Continuous assessment of cardiac output during exercise using real time flow with fast GPU reconstruction
}

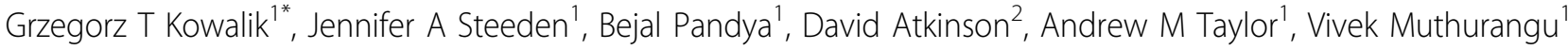 \\ From 15th Annual SCMR Scientific Sessions \\ Orlando, FL, USA. 2-5 February 2012
}

\section{Background}

The haemodynamic response to exercise is an important health marker. Phase contrast MR (PCMR) is an accurate method of assessing cardiac output and novel realtime sequences allow assessment of flow during exercise. However, such sequences often have time-consuming reconstruction algorithms, which prevent continuous cardiac output monitoring during exercise.

Graphical processing units (GPU) with multiple processors offer the possibility of performing extremely fast reconstruction of real-time MR data. Such reconstructions would make continuous assessment of cardiac output during exercise possible and this projects aim to validate this approach.

\section{Methods}

Twenty healthy volunteers underwent aortic flow assessment using spiral SENSE real-time PCMR (12 interleaves, 4-fold SENSE acquisition, $43 \mathrm{~ms}$ temporal resolution, 13980 frames, acquisition time 10 minutes). Aortic flow was measured continuously during a ramped cycle exercise (2-16 W, increased every minute by $2 \mathrm{~W})$. The online iterative SENSE reconstruction was implemented in CUDA and performed on a bi-directionally networked computer (GPU card: NVidia Geoforce 480).

The GPU reconstruction task was split into batches of sixty frames with incoming data being buffered on CPU RAM, which allowed overlapping between data transmission and reconstruction.

Aortic flow images were analysed using a semi-automated optic-flow registration and segmentation

${ }^{1}$ Centre for Cardiovascular MR, UCL, Institute of Cardiovascular Science, London, UK

Full list of author information is available at the end of the article algorithm. The algorithm was implemented as a multithreaded application to speed-up processing time.

\section{Results}

The new GPU implementation was tested and compared against our original CPU version. A single batch of 60 flow measurements was retrospectively reconstructed with both versions. GPU implementation showed negligible bias in stroke volume of $-0.4 \mathrm{ml}$ and good limits of agreement -1.9 to $1.2 \mathrm{ml}$.

A single batch of 60 frames reconstructed 7.7 times faster on the GPU than CPU (15.2 if time required for data transmission is excluded). Total reconstruction time for the 13980 frames (including transmission and buffering) was $\sim 626 \mathrm{~s}$. Thus, data was available for use $\sim 9 \mathrm{~s}$ after the scan finished. This is a 556 times speed-up compared to the estimated CPU reconstruction (of $\sim 83 \mathrm{~min}$ ).

Fig 1 shows a representative plot of continuous heart rate and cardiac output changes during exercise in one volunteer.

\section{Conclusions}

Continuous assessment of flow during exercise could provide a novel way of assessing hemodynamic responses in patients. Unfortunately, real-time MR sequences have long reconstructions that would leave the clinician waiting for more than an hour for the data. We have shown that by performing a GPU reconstruction, the data can be used within seconds of the acquisition finishing. Furthermore using this technique we have been able to show the expected response to continuous exercise in healthy volunteers. 


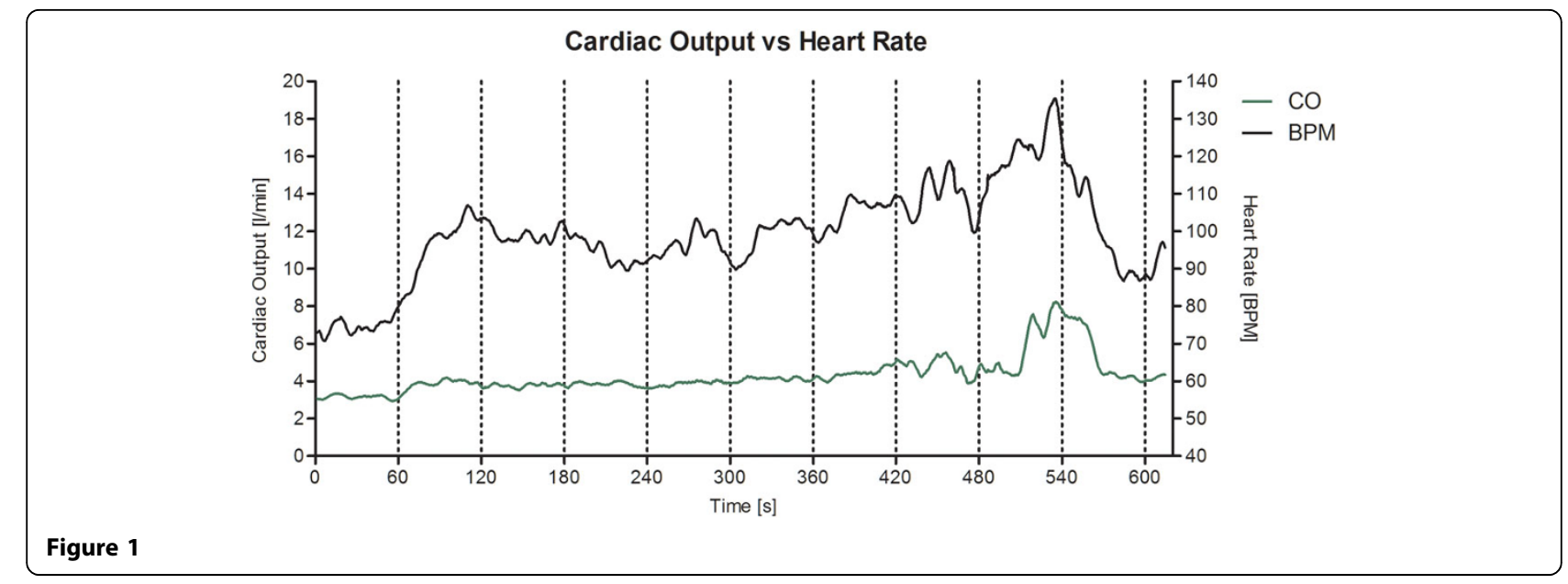

\section{Funding}

British Heart Foundation.

\section{Author details}

${ }^{1}$ Centre for Cardiovascular MR, UCL, Institute of Cardiovascular Science, London, UK. ${ }^{2}$ UCL Department of Medical Physics \& Bioengineering, Centre for Medical Image Computing, London, UK.

Published: 1 February 2012

doi:10.1186/1532-429X-14-S1-P232

Cite this article as: Kowalik et al.: Continuous assessment of cardiac output during exercise using real time flow with fast GPU

reconstruction. Journal of Cardiovascular Magnetic Resonance 201214 (Suppl 1):P232.

Submit your next manuscript to BioMed Central and take full advantage of:

- Convenient online submission

- Thorough peer review

- No space constraints or color figure charges

- Immediate publication on acceptance

- Inclusion in PubMed, CAS, Scopus and Google Scholar

- Research which is freely available for redistribution 